\title{
SÍNDROME DE BAZEX ASOCIADO A CARCINOMA DE OROFARINGE. DESCRIPCIÓN DE UN CASO
}

\section{Bazex syndrome related to oropharyngeal carcinoma. Case report}

\author{
Natalia CASTAÑEDA-CURTO ${ }^{1}$, María MARTINO-GONZÁLEZ², Carmelo MORALES-ANGULO³ \\ ${ }^{1}$ Hospital de Laredo. Servicio de Otorrinolaringología. Laredo. Cantabria. ${ }^{2}$ Hospital Universitario Marqués de \\ Valdecilla. Servicio de Anatomía Patológica. Santander. Cantabria. ${ }^{3}$ Hospital Universitario Marqués de Valdecilla. \\ Servicio de Otorrinolaringología. Santander. Cantabria. España.
}

Correspondencia: nataliauc@gmail.com

Fecha de recepción: 2 de abril de 2018

Fecha de aceptación: 14 de abril de 2018

Fecha de publicación: 16 de abril de 2018

Fecha de publicación del fascículo: 1 de septiembre de 2019

Conflicto de intereses: Los autores declaran no tener conflictos de intereses

Imágenes: Los autores declaran haber obtenido las imágenes con el permiso de los pacientes Política de derechos y autoarchivo: se permite el autoarchivo de la versión post-print (SHERPA/RoMEO)

Licencia CC BY-NC-ND. Licencia Creative Commons Atribución-NoComercial-SinDerivar 4.0 Internacional Universidad de Salamanca. Su comercialización está sujeta al permiso del editor

RESUMEN: Introducción y objetivo: el síndrome de Bazex es un cuadro paraneoplásico infrecuente que se asocia generalmente a carcinoma epidermoide de vía aerodigestiva superior. Se presenta un caso de Síndrome de Bazex característico para contribuir a un diagnóstico precoz de la patología tumoral subyacente asociada. Descripción del caso: varón de 57 años, fumador y bebedor importante, que acude a consulta por tumor laterocervical izquierdo de meses de evolución asociado a eccema descamativo y violáceo en manos, pies, pabellones auriculares y rodillas. Tras exploración y pruebas complementarias se establece el diagnóstico de carcinoma epidermoide amigdalar T2N3M0 y síndrome paraneoplásico asociado. Conclusiones: El carcinoma de orofaringe constituye uno de los tumores más frecuentes asociados a síndrome de Bazex. Por tanto, ante esta manifestación cutánea, siempre debemos descartar patología oncológica a dicho nivel. 


\section{SÍNDROME DE BAZEX ASOCIADO A CARCINOMA DE OROFARINGE. DESCRIPCIÓN DE UN CASO \\ CASTAÑEDA-CURTO N ET AL}

PALABRAS CLAVE: síndrome paraneoplásico; acrodermatitis; carcinoma; orofaringe.

SUMMARY: Introduction and objective: Bazex syndrome is an infrequent paraneoplastic syndrome that is related to an upper aerodigestive epidermoid carcinoma. A case of characteristic Bazex syndrome is presented to contribute to an early diagnosis of the associated underlying tumor pathology. Case description: 57-year-old male, smoker and regular drinker, presented with a cervical mass associated with scaly and violaceous eczema on hands, feet, ears and knees. After examination and complementary tests, the diagnosis of T2N3M0 tonsillar squamous cell carcinoma and paraneoplastic syndrome was established. Conclusions: Oropharyngeal carcinoma is one of the most frequent tumors associated with Bazex syndrome. Therefore, if we observe these skin lesions, we should always rule out oncological pathology at that level.

KEYWORDS: paraneoplastic syndrome; acrodermatitis; carcinoma; oropharynx.

\section{INTRODUCCIÓN}

La acroqueratosis de Bazex es un síndrome paraneoplásico que cursa con una dermatosis psoriasiforme de predominio acral [1]. Las orejas y las uñas son las zonas más frecuentemente afectadas, seguidas de la nariz, manos y pies [2]. Predomina en varones caucásicos de más de 40 años de edad y generalmente se asocia a carcinoma escamoso del tracto aerodigestivo superior o de la región cervicomediastínica $[1,3,4]$, pudiendo preceder a la aparición de la patología tumoral en el 65 al $70 \%$ de los casos [1,2].

Las lesiones cutáneas mejoran con el tratamiento del tumor, de modo que si persisten o reaparecen debe sospecharse la recurrencia tumoral o metástasis [2].

\section{CASO CLÍNICO}

Presentamos el caso de un varón de 57 años de edad, fumador de 80 paquetes de tabaco al año y bebedor moderado. Acudió a consulta de otorrinolaringología por un tumor laterocervical izquierdo de tres meses de evolución de crecimiento progresivo. Además, presentaba ya previamente a la aparición del tumor una erupción descamativa con coloración violácea en manos y pies con distrofia ungueal (Figura 1), pabellones auriculares y rodillas, que no mejoraba con tratamiento tópico hidratante pautado por su dermatólogo.

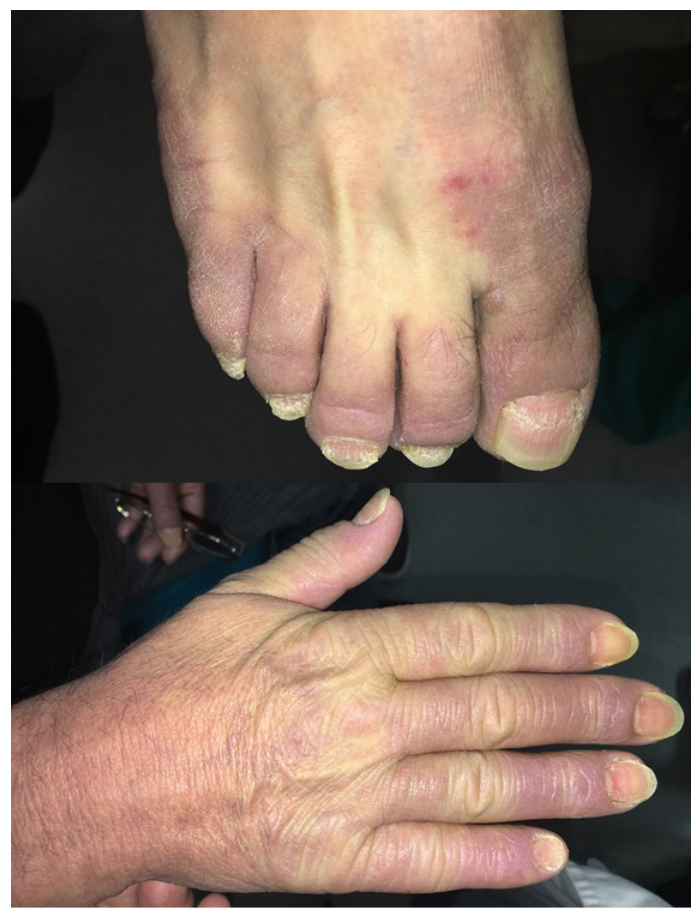

Figura 1. Lesiones psoriasiformes violáceas en pies y manos con afectación ungueal.

No asociaba disnea, disfagia, odinofagia o disfonía. La exploración ORL puso de manifiesto una irregularidad en el lecho amigdalar izquierdo con eritema, sin claras lesiones en la mucosa, así como una masa tumoral laterocervical izquierda alta de 


\section{SÍNDROME DE BAZEX ASOCIADO A CARCINOMA DE OROFARINGE. \\ DESCRIPCIÓN DE UN CASO \\ CASTAÑEDA-CURTO N ET AL}

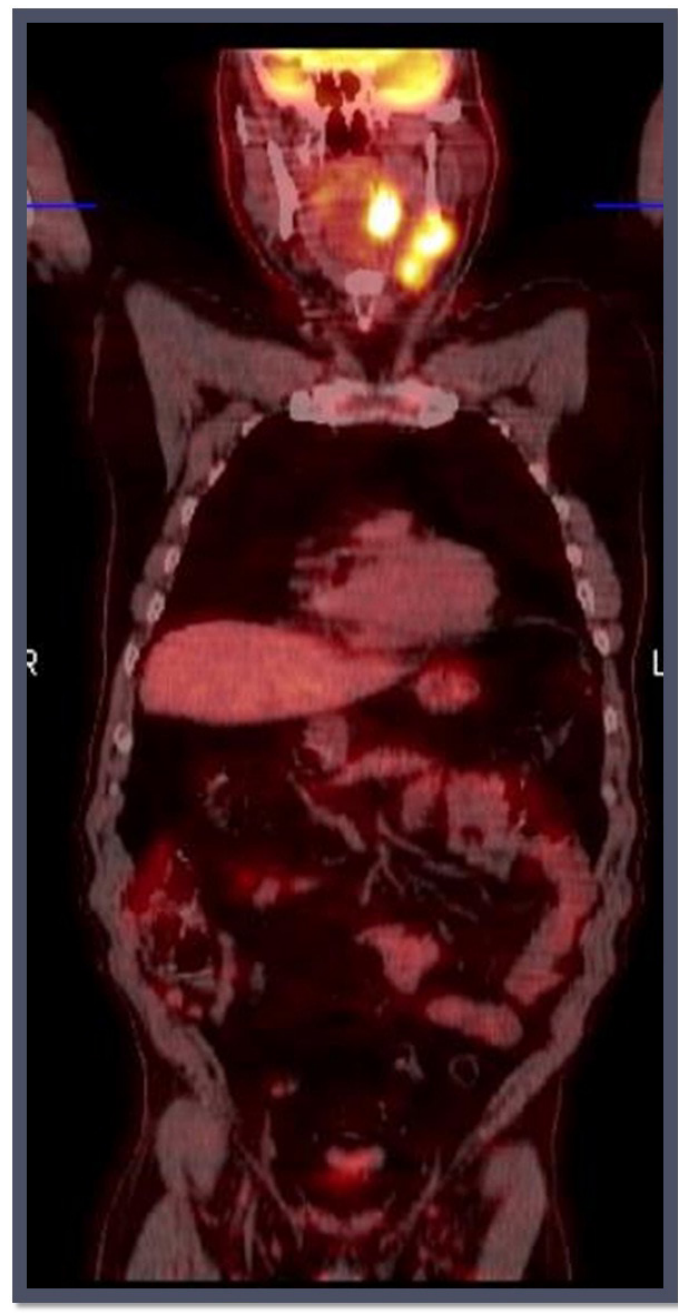

Figura 2. Imagen de PET-TC donde se objetiva captación en orofaringe izquierda, así como en conglomerado adenopático laterocervical ipsilateral.

6 a 7 centímetros de diámetro aproximadamente, dura y adherida a planos profundos. Ante estos hallazgos se realizó biopsia profunda en región amigdalar izquierda, siendo informado como carcinoma epidermoide. Además, el análisis molecular del virus del papiloma humano mediante técnica PCR, identificó los tipos 16 (alto riesgo) y 81 (bajo riesgo). En la tomografía por emisión de positrones
(PET-TAC) se evidenció una lesión hipercaptante en amígdala izquierda, así como conglomerado adenopático izquierdo hipercaptante de $10 \mathrm{~cm}$ de diámetro mayor sin signos de metástasis a distancia (Figura 2). Con estos hallazgos se estableció el diagnóstico de carcinoma epidermoide de orofaringe T2N3M0 y por consenso del comité oncológico de cabeza y cuello se inició tratamiento con cisplatino y radioterapia concomitante. Tras el primer ciclo de cisplatino, el paciente presentó una mucositis severa y una hepatitis aguda grave, por lo que fue ingresado en cuidados intensivos donde falleció pocos días después por insuficiencia hepática.

\section{DISCUSIÓN}

En 1965, Bazex et al. describieron por primera vez este síndrome paraneoplásico asociado a carcinoma de lengua [5]. Posteriormente la publicación de casos similares en 1967 confirmó este hallazgo caracterizado por erupción psoriasiforme en regiones acrales asociadas a enfermedad tumoral [4]. El mecanismo por el que se produce este síndrome no está del todo claro. Una teoría es la existencia de mimetismo molecular, una reacción cruzada entre antígenos tumorales y receptores del factor de crecimiento en las células epidérmicas. Otra explicación posible implica la interacción directa entre la piel y las citocinas secretadas por las células tumorales, como el factor de crecimiento transformante y el factor de crecimiento similar a la insulina [2,6]. Niveles bajos de vitamina A sérica también podrían influir en el desarrollo de las lesiones cutáneas características $[3,4]$. El síndrome de Bazex se caracteriza por lesiones cutáneas psoriasiformes de color violáceo, siendo las zonas más afectadas los pabellones auriculares (79\%), uñas (75\%), nariz (63\%), dedos (61\%), manos (57\%) y pies $(50 \%)$ [7]. En el paciente que comentamos además había afectación de las rodillas. Las manifestaciones cutáneas a menudo preceden al diagnóstico de cáncer en aproximadamente 2 a 6 meses en un 65\% a 70\% de los pacientes; con menor frecuencia, ocurren 


\section{SÍNDROME DE BAZEX ASOCIADO A CARCINOMA DE OROFARINGE. DESCRIPCIÓN DE UN CASO \\ CASTAÑEDA-CURTO N ET AL}

simultáneamente (10\% a $15 \%)$ o después del diagnóstico tumoral (15\% a 25\%) [8]. Histopatológicamente los hallazgos de las lesiones cutáneas son inespecíficos, con hiperqueratosis, paraqueratosis focal, acantosis moderada e infiltración linfocítica de la dermis [2].

Aproximadamente el $80 \%$ de los casos se asocian a carcinoma de la región aerodigestiva alta. $[2,8]$. La metástasis a los ganglios linfáticos cervicales parece ser común en pacientes con síndrome de Bazex. En un estudio retrospectivo de 113 pacientes con síndrome de Bazex, Bolognia et al [4] describieron como tumor primario: orofaringe y laringe $(48,6 \%)$, pulmón $(17,7 \%)$, ubicación desconocida (16\%), esófago (10,6\%, uno de ellos con un carcinoma de seno piriforme asociado), y casos aislados en la próstata, hígado, estómago, útero, vulva y médula ósea. Las lesiones van desapareciendo con el tratamiento del tumor primario, de modo que su reaparición nos debe hacer pensar en recurrencia tumoral o metástasis. Se han probado además otros tratamientos sin mucho éxito como queratolíticos, corticoides tópicos o radiación UVB [2].

\section{CONCLUSIONES}

El carcinoma de orofaringe constituye uno de los tumores más frecuentes asociados a síndrome de Bazex. Por tanto, ante esta manifestación cutánea, siempre debe descartarse patología oncológica a dicho nivel.

\section{BIBLIOGRAFÍA}

1. Villares Soriano J, Vázquez Barro C, Martínez Vidal J. Acroqueratosis de Bazex como síndrome paraneoplásico. Acta Otorrinolaringol Esp. 2014;65:138-9.

2. Squires B, Daveluy SD, Joiner MC, Hurst N, Bishop M, Miller SR. Acrokeratosis Paraneoplastica Associated with Cervical Squamous Cell Carcinoma. Case Rep Dermatol Med. 2016;2016:7137691.

3. Fasanmade A, Farrell K, Perkins CS. Bazex syndrome (acrokeratosis paraneoplastica): persistence of cutaneous lesions after successful treatment of an associated oropharyngeal neoplasm. Br J Oral Maxillofac Surg. 2009;47:138-9.

4. Bolognia J, Brewer Y, Cooper D. Bazex syndrome (acrokeratosis paraneoplastica). An analytic review. Medicine (Baltimore). 1991;70:269-80.

5. Bazex A, Salvador R, Dupré A, Christol B. Syndrome paranéoplasique à type d'hyperkératose des extremités. Guérison après le traitement de l'épithelioma laryngé. Bull Soc Fr Dermatol Syphiligr 1965;72:182.

6. Hempen A, Samartzis EP, Kamarachev J, Fink D, Dedes KJ. Acrokeratosis paraneoplastica in serous ovarian carcinoma: case report. BMC Cancer. 2015;15:507.

7. Poligone B, Christensen SR, Lazova R, Heald PW. Bazex syndrome (acrokeratosis paraneoplastica). Lancet. 2007;369(9560):530.

8. Silva JA, Mesquita KC, Igreja AC, Lucas IC, Freitas AF, Oliveira SM et al. Paraneoplastic cutaneous manifestations: concepts and updates. An. Bras. Dermatol.2013;88(1):9-22. 